\title{
SOCIEDAD CIVIL Y ESTADO EN LA FILOSOFÍA DEL DERECHO DE HEGEL")(II)
}

\section{Ramón Valls Plana}

\section{Estratos constitutivos del sujeto europeo moderno}

En el texto que acabo de comentar ${ }^{(* *)}$, además del estado y la sociedad civil, aparece la persona como «momento» lógico igualmente esencial al todo social. Vale la pena detenernos aquí un momento, no sólo por razones obvias, sino también porque en este punto reside el máximo de concesiones que Hegel puede hacer al individualismo moderno dentro de un cuerpo de doctrina netamente pro-social. El individuo europeo moderno, tal como Hegel lo concibe, está formado por un conjunto de estratos superpuestos que vienen a ser sedimentación permanente de experiencias históricas. Aquí hay, creo, una manera sutil de restablecer la anamnesis platónica. Las experiencias (a posteriori, diríamos) vienen a constituir el sujeto y sus modos de actuación (su a priori). Bajo esta perspectiva cobra sentido aquella tesis filosóficamente escandalosa que afirmaba que la existencia precede a la esencia o que la naturaleza no es tal, sino una combinación entre otras que en abstracto eran igualmente probables, pero que en concreto viene a resultar estable y estabilizada (estatalizada, podríamos decir, estirando el hilo) porque era más lógica. Cuando la acción se produce, aquel $a$ priori se reactiva o rememora. Se hace presente entonces como portador de aquella lógica que le otorga substancialidad.

\footnotetext{
* Traducción del catalán de Daniel A. Attala

** Enz $\$ 198$. El comentario en: TOPICOS. N 5. Santa Fe. 1998. p. 21-27
} 
1) El primer estrato de la subjetividad no es demasiado explícito en la Filosofia del Derecho. Corresponde a desarrollos que figuran en la Fenomenología del Espíritu, cap. IV principalmente, y que se hacen presentes en la Filosofía del Derecho de manera estilizada o abreviada. Hablo del estrato de la autoconsciencia humana que, constituída inicialmente por el deseo (de raíz hobbesiana y spinoziana). busca el reconocimiento de otra autoconsciencia. Este reconocimiento viene a ser como el hecho inaugural de la historia humana que da lugar a las formas más primitivas de sociedad. El reconocimiento es desigual y con él se origina una sociedad de señores y esclavos.

La dialéctica del deseo que busca el reconocimiento del otro a través de la lucha a muerte. evoca ciertamente a Hobbes. pero también la Política de Aristiteles, pues el reconocimiento acaece en el seno del lenguaje y la división del género humano en señores y siervos es contemplada igualmente al comienzo de la Politeia como división social básica. En relación con eso, ciertamente, hay que leer el $\S 258 F D$ con su larga nota y el añadido, pero también hay que ver que en las primeras páginas del libro $(\$ 4$, final de la N) Hegel advierte que cada lector podrá encontrar en su autoconsciencia representaciones que le ayudarán a entender los desarrollos conceptuales que irá encontrando a lo largo del libro. A partir de este y de otros textos, Ilting ha propuesto incluso una lectura «fenomenológica» de la $F D$ que se contrapondría a la lectura «lógica» más explícitamente avalada por los textos (1). Es cierto por otro lado que en la Enciclopedia, en textos prácticamente contemporáneos a los de la $F D$, se puede ver la pervivencia en el últi-

\footnotetext{
(1) Heinz Ilting Karl. Rechtsphilosophie als Phänomenologie des Be'wußtseins der Freiheit. En Hegels Philosophie des Rechts. hrsgb. von Dieter Henrich und Rolf-Peter Horstmann. Stuttgart. Klett-Cotta. 1892. p. 225 ss.
} 
mo Hegel, de su concepción del reconocimiento mutuo de las autoconciencias como base de cualquier comportamiento ético ${ }^{(2)}$. En este primer estrato los individuos están ya, por tanto, socialmente vinculados.

2) El segundo estrato lo encontramos desarrollado en los $\S \S 34$ y ss. de la $F D$ y lo podemos formular así: Todo ser humano, por el hecho de serlo, es en principio persona jurídica o sujeto de derecho, no solamente capaz de propiedad privada sino necesitado de ella desde su libertad; este derecho sin embargo es derecho indeterminado y abstracto («natural» en terminología antigua) a poseer algo. sin que ningún análisis conceptual de él pueda determinar el cómo ni el cuánto de la posesión. Es por tanto un derecho más potencial que real y exige ser concretado, pero la concreción sólo le puede llegar socialmente. Si este derecho se concibe como «natural» es necesario añadir entonces, seguidamente, y con Hobbes, que la primera obligación que nos dicta el estado de naturaleza es precisamente la de salir de él (exeundum est ab statu naturae). Propiamente hablando, a este derecho en algún sentido embrionario no se lo ha de llamar «natural», porque deriva de la libertad y es su cuerpo. Esta lo necesita como primer ámbito irrenunciable de ac-

\footnotetext{
(2) Enz3 436. "La autoconciencia universal es el saber afïrmativo de sí mismo en otro sí mismo. cada uno de los cuales. como singularidad libre. tiene autosuficiencia absoluta. pero en virtud de la negación de su inmediatez o deseo no se distingue de la otra. es universal y objetiva. $y$ la universalidad real como reciprocidad la tiene [cada una] sabiéndose reconocida en el otro libre. y eso lo sabe en tanto ella reconoce al otro y lo sabe libre». Y prosigue la nota: "Esta reaparición universal de la autoconciencia. el concepto. el cual se sabe como subjetividad idéntica consigo en su objetividad. y que por ello se sabe universal. es la forma de la conciencia de la sustancia de toda espiritualidad esencial. de la familia. de la patria. del estado: lo es igualmente de todas las virtudes. del amor. de la amistad. de la valentía. del honor y de la fama. Pero este aparecer de lo substancial puede también separarse de lo sustancial y mantenerse de por sí como honor sin contenido, prestigio hueco, etc".
} 
tuación, si es que ha de ser libertad real; en todo caso es derecho, es humano y es histórico ${ }^{(3)}$.

Este derecho primario lo contempla Hegel a veces como procedente de la rebelión individualista de los sofistas contra la polis, rebelión que, pasada a través de Sócrates y Antígona, pero no a través de Platón ya que él no supo cómo integrarla, acaba disolviendo la polis griega y puede disolver la sociedad civil moderna, como diremos más adelante. El derecho primario se formaliza como derecho de la persona a la propiedad en el derecho romano; se generaliza cuando se extiende a todos los ciudadanos del imperio, se interioriza por obra del cristianismo como consecuencia de la libertad individual, y cuando se ha hecho cosa de todos, mina las bases de la esclavitud en todas sus formas. Es ya derecho irreversible porque su aparición histórica es fenómeno adecuado de libertad y allí despierta, por tanto, el concepto. De este derecho deriva primariamente el derecho civil, el cual es básicamente según Hegel regulación de la posesión y del contrato; a un nivel superior específicamente ético será después patrimonio familiar y herencia. Su lesión origina el contencioso civil pero también abre el espacio

\footnotetext{
(3) En las páginas de la $F D$ de Hegel dedicadas al derecho de propiedad es donde se encuentra la noción más primaria de derecho inserta en un contexto relacional esquematizable como persona-cosa-persona. De todas maneras las páginas de llegel sobrepasan continuamente cualquier esquematismo y por eso resultan llenas de sugerencias de todo tipo. Su lectura se hace especialmente fecunda si se compara el desarrollo hegeliano con las páginas paralelas de Kant (cf. .Metafisica de las_costumbres trad. cast. cit.. p. 55 ss). Quizá cuando se repite que los franceses hicieron la revolución y los alemanes la pensaron se quiere aludir a estos textos. Recordemos solamente que el derecho de propiedad figuraba como derecho del hombre y del ciudadano (derecho "inviolable y sagrado" que sigue inmediatamente a la libertad) en la Declaración de la Asamblea Nacional Francesa del 27 de agosto de 1789 (arts. 2 y 17) y que la primera edición de la . Vetafisica de las ('ostumbres es de 1796 o 1797. En substancia puede decirse que el texto de Hegel sigue el orden del de Kant. aún cuando Hegel lo transforma profundamente en función de la concepción diferente de la libertad y el arbitrio.
} 
del derecho penal cuando la lesión de la propiedad y la persona es dolosa. Estas consecuencias del derecho de propiedad exigen igualmente organización social, p.e. ley y juez para acabar con el talión y con la dinámica «natural» de la venganza. En resumen, persona y propiedad por un lado, y sociedad civil y estado por la otra, se exigen mutuamente. El derecho de propiedad, precisamente porque es fundamental y abstracto en su «naturalidad», hace necesaria la sociedad para darle realidad, contenido y protección. Por otro lado la sociedad necesita el derecho de propiedad como columna para su estabilidad.

3) El tercer estrato podemos formularlo así: Todo ser humano, por el hecho de serlo, es sujeto moral ( $F D \S 105$ y ss.). En esta afirmación culmina la interiorización de la libertad y responsabilidad cristianas, pero transformadasen autonomía moral kantiana. Históricamente, por tanto, se sobrepone al estrato anterior, aunque conceptualmente la libertad moral ha de considerarse más profunda. Ya no es algo vuelto hacia fuera, como el derecho de la persona a la propiedad, sino que es netamente interior. Pero Hegel cree que a pesar de su naturaleza intimista, la moralidad es también un derecho fundamental y derecho auténtico $(F D \S 107)$ pues la conciencia moral es elemento principalísimo de la dignidad humana que ha de ser respetada por los otros y puede entrar en colisión con otros derechos. No obstante, como las determinaciones propias de la moralidad no pueden legislarse, porque son internas, solamente se podrá positivar jurídicamente la protección externa de la conciencia.

Este estrato del sujeto se ha generado históricamente,como si dijéramos, por profundización de la conciencia cristiana, la cual se autoinculpa en el delito y así deviene responsable. Hay que observar que el delito es tal porque no solamente atenta contra el cuerpo de una persona o sus propiedades, sino que es lesión del 
derecho en sí, dice Hegel, es lesión del universal o del derecho de todos; atenta contra el orden de la libertad.

Con el estrato de la conciencia moral tenemos aquello que Hegel llama el sujeto europeo moderno, bien posesionado de la autoconciencia de la libertad. En la $F D$ Hegel no devalúa nada esta conciencia tan kantiana y rousseauniana, pre-revolucionaria y enemiga potencial de la propiedad. Pero su profundo radicalismo la divorcia del mundo real como lo hace también el cristianismo del que procede. Y separada del mundo en forma de exquisita alma bella romántica, la buena conciencia deviene necesariamente conciencia hipócrita. Es necesario leer la serie de las siete figuras de la hipocresía moderna que preparan la transición de la moralidad a la eticidad en la $F D(\S 40)$ a fin de ver a Hegel verdaderamente obsesionado por hacer real la moralidad como libertad en la exterioridad social, lejos sin embargo de moralismos.

4) Ahora se ha de decir: todo ser humano es sujeto social o, dicho de otra manera, la relación a otra libertad es constitutiva de la libertad, de tal manera que la libertad de uno solamente deviene real en [relación a] la libertad de otros. Este nivel que Hegel quiere contemporáneo de él (post-revolucionario), Bobbio cree que no se ha acabado de dar de hecho, cosa que tiñe de utopismo la teoría hegeliana del estado. Lo veremos al final de este trabajo. El imperativo categórico del sujeto moral que encontramos en el estrato anterior le manda salir de sí para dotar de contenidos reales su obligación formal. Es (ha de ser) un sujeto que forma comunidad, primeramente familiar (se casa) después social (trabaja) y finalmente política (participa patrióticamente en los asuntos públicos con el desinterés que le da la conciencia de universalidad). Este sujeto que Hegel ve como su contemporáneo reencuentra el primer estrato y, con él, la serenidad griega de la vida (Wir sind die Griechen! Somos los griegos!, gritaban los jóvenes idealistas a finales del s. XVIII). 
Hegel cierra así el ciclo que desde los clásicos llega a nosotros pasando por la escisión cristiana.

\section{La idea ética y sus tres cuerpos}

Podemos dar ahora la tercera y última caracterización más concreta de la relación sociedad civil-estado. Pero antes hay que entender el uso que hace Hegel de la palabra «idea». De momento será suficiente, como él mismo hace, con el $\S 1$ de la $F D$. Idea no es para él representación mental como lo supone el uso lingüístico corriente, sino realidad inteligible (como lo era en Platón), pero no situada en un mundo más allá, sino objetivamente presente en este mundo de aquí con el que tropezamos cada día. Entendiéndola entonces como mundana, Hegel denomina «idea» a aquella realidad que es concepto realizado o realidad adecuada a su concepto. El concepto se puede comparar al alma y la realización al cuerpo. Así, entonces, tal como hay cuerpos bien hechos (atletas) y cuerpos mal hechos (gibosos) hay instituciones históricas que tienen estructura o alma racional, lo cual no impide que también haya monstruosas realidades brutas, como por ejemplo la tiranía. Las primeras son idea, las segundas no.

Dicho eso, tendrá sentido añadir que para Hegel hay tres cuerpos o grandes instituciones sociales que son idea, las cuales, ya que son instituciones de la libertad intersubjetiva, son idea ética: familia, sociedad civil y estado. La eticidad se define en el importante $\S 142^{(+)}$que podemos sintetizar así:

\footnotetext{
(t) "L a eticidad es la idea de la libertad como bien viviente que tiene en la autoconciencia su saber. su querer $y$. por medio de su actuar, su realidad; actuar que por su lado tiene en el ser ético su fundamento en sí y para sí. y su fin motor. Es el concepto de la libertad que ha devenido mundo disponible y naturaleza de la autoconciencia.»
} 
1) La eticidad es la idea de la libertad; es por tanto concepto y figura $o$, dicho de otra manera, institución histórica verdadera, no falsa.

2) Es el bien supremo; es entonces aquello bueno que la doctrina moral ha contemplado tantas veces como valor máximo, pero que en Hegel no es ya un bien abstracto y trascendente, como lo veían los antiguos y sobre todo todavía la moralidad kantiana, sino encarnado en los organismos sociales vivos y efectivos.

3) Su dimensión subjetiva es la autoconcienciahumana, la cual incluye saber que interioriza la realidad social y voluntad que la transforma con la acción exterior.

4) $\mathrm{Si}$, pues, la acción arranca de la realidad ética misma o cuerpo social, y pasando por la conciencia retorna a la realidad de la que salió modificándola, Hegel no es de ningún modo un «idealista» en el sentido vulgar, sentido que supone que la acción realizadora tiene su origen en las «ideas» de la conciencia.

5) El concepto objetivo inmanente a la idea promueve no solamente su realización sino que es también su finalidad. La realidad se esfuerza siempre (recuerden el conatus spinoziano), podríamos decir, para devenir más adecuada al concepto y hacerse así también más verdadera y efectiva. El texto lo indica muy lacónicamente con la terminología aristotélica del motor que atrae finalísticamente.

6) En resumen, por tanto, la idea ética «es el concepto (objetivo) de la libertad que ha devenido mundo existente (vorhandene Welt) como una suerte de segunda naturaleza exterior de la autoconciencia, es decir, del ser humano. Aún, en el $\$ 144$, se añade que lo ético no es como lo moral (formal e interior) sino que tiene un contenido que, en tanto conceptual, es necesario y es tam- 
bién una realidad exterior bien definida o concreta que «se eleva por sobre la opinión subjetiva y el arbitrio»; esta realidad es «las institucionesy las leyes».

No haré un repaso detallado del tratamiento hegeliano de la familia, que tiende, me parece, hacia una cierta privatización. Al menos en la esquematizaciónya estudiada que se encuentra en $E n z 3$ $\S 198 \mathrm{~N}$, matrimonio y familia no aparecen explícitamente y cabe suponer que quedan absorbidas allí en el «momento» de las personas. Sólo de pasada diré que Hegel rechaza airadamente la doctrina tradicional que contempla el matrimonio como un contrato $(F D$ $\S 161 \mathrm{Agr}$.). Las relaciones éticas fundamentales ya no son ni pueden ser objeto de contrato porque los contratos son sobre cosas y nunca sobre personas. Una persona objeto de contrato sería un objeto de posesión y por tanto un esclavo, un ser humano tratado como una cosa ${ }^{(5)}$. Y más arriba ya hemos dicho que tampoco los estados pueden tener su origen en un pacto. Eso es así en todos los casos porque el vínculo social es previo. Por lo que hace a la familia en particular, Hegel estudia, además del matrimonio, el patrimonio y la educación de los hijos; un proceso, este último, que los arranca de la familia y los inserta en la sociedad civil.

\footnotetext{
(5) Contra Kant (cf: . Metafisica de las ('ostumbres 22 ss: trad. cast. p. 96 ss. y también p. 198 y ss.). Hegel no puede entender el invento kantiano de un derecho personal de caracter real (dinglich. vale decir. cósico) como "derecho a poseer un objeto externo como una cosa y usarlo como una persona. El invento realmente no dice demasiado en favor de Kant si ponemos atención en que el «objeto externo» es la esposa (o el esposo). el hijo y el criado. (los cuales son precisamente personas!) No se entiende en qué puede consistir usar un objeto como una persona. a menos que querramos pensar en animales de compañía. L a definición quizá debía decir. si quería ser clara. "derecho a usar una persona como una cosa». pero entonces resultaba demasiado clara. era escandalosa y entraba en contradicción con el mandato fundamental de la ética kantiana de no tomar jamás a la otra persona como un medio (Ibid. 2a. parte. I. Doctrina ética elemental 25).
} 


\section{Suficiencia e insuficiencia de la sociedad civil}

Volviendo ahora finalmente a nuestro asunto principal, hay que repetir en primer lugar que para Hegel la sociedad civil es un fenómeno históricamente moderno que de ninguna manera puede considerarse como una contingencia histórica que tanto podría ser como no. Encarna una dimensión necesaria del concepto, la particularidad, y es el campo de realización del derecho fundamental a la propiedad. La sociedad civil es por tanto racional y, por el hecho de que es en sí necesaria, tarde o temprano tenía que aparecer. Una vez aparecida históricamente, según un orden cronológico que no es el orden lógico ( $F D \S 182$ ), es irreversible, como lo es todo fenómeno con esencia verdaderamente racional ${ }^{(6)}$.

El importante $\S 182$ de la $F D$ con el que comienza el tratamiento de la sociedad civil y ofrece una visión global de ella casi no exige explicación porque de hecho la hemos estado haciendo a lo largo de todo este trabajo ${ }^{(7)}$. Aquí llamaré solamente la atención sobre el hecho de que Hegel en este parágrafo no da propiamente

\footnotetext{
(6) Cabe así recordar el tratamiento kantiano de la revolución francesa como un hecho que provoca el aplauso general y desinteresado. Siendo así la revolución fenómeno de libertad (en sí nouménica) se hace irreversible y fortifica la esperanza en el progreso moral de la humanidad. Se puede ver en el cap. 6. Si el género humano se encuentra en progreso continuo hacia lo mejor (año 1798) en: Kant Emmanuel, Filosofia de la historia. Pról. y trad. de Eugenio Imaz. México. F('E. 1978.

(7) "La persona concreta que es para ella misma fin particular aunque [es] un todo de necesidades [Bediurfnisse] y una mezcla de necesidad [. Totwendigkeit] natural y arbitrio. es uno de los principios de la sociedad civil: pero la persona particular [es este principio] aunque [está] esencialmente referida a otra particularidad de la misma clase. de tal manera que cada una de ellas se hace valer y se satisface mediada por la otra. y a la vez simplemente [mediada] por la forma de la universalidad. [el cual es] el otro principio [escondido de la sociedad civil]. [Agr. | La sociedad civil es lo diferenciado [y no indiferente o neutrol que se interpone entre la familia y el estado. aunque su formación es posterior a la del estado: en efecto. por el hecho de que es lo diferenciado presupone el estado. al que ella como autosuficiente ha de tener delante para subsistir. Por otro lado. la creación de la sociedad civil es propia del mundo moderno. el cual es
} 
una definición de sociedad civil como correspondería. La falta seguramente se debe al hecho de que la sociedad civil, aún siendo un organismo diferenciado dentro de la sociedad, no acaba de tener una esencia compacta, por decirlo así. La particularidad es ciertamente la esenciá, pero la particularidad sola es una fuerza disgregadora incapaz de formar unidad. Es claro que la sociedad civil de hecho no estalla, pero su permanencia no la hemos de atribuir a la particularidad sino a la universalidad que también le está presente primero en forma de interdependencia en la satisfacción de las necesidades y en segundo lugar por imposición del estado mediante las leyes. Hay que considerar sin embargo que esta dimensión de universalidad permanece en la sociedad civil como una especie de trasfondo oculto y si, además, hemos aprendido ya que «universalidad» en lenguaje lógico significa «estado» en el mundo social, resulta que el estado es quien libra a la sociedad civil de la disolución. Tanto es así que ahora se ha de hacer bien patente cómo el tratamiento hegeliano intenta hacer aparecer el vínculo de pro-

aquel que comienza a hacer posible el derecho de todas las determinaciones de la idea. (uando el estado se representa como una unidad de personas distintas, o sea. como una unidad que es solamente comunidad [(jemeinschaft. ser conjuntamente. no Gesellschaft o auténtica sociedad| se piensa solamente en la determinación [propial de la sociedad civil. Muchos tratadistas políticos modernos [los teóricos del pacto, los atomistas sociales| no han podido aportar otra visión del estado lque aquella propia de la sociedad civill. En la sociedad civil cada uno es fin para sí mismo. todo el resto no es nada para él. Pero sin la referencia a los otros no puede conseguir el ámbito total de sus fínes: los otros son. por tanto. medio para el fin del [individuol particular. Sin embargo. el fin particular se da la forma de la universalidad a través de la referencia a los otros. $y$ se satisface dando satisfacción a la vez al bienestar del otro. Y como sea que la particularidad está vinculada al condicionamiento por parte de la universalidad. la totalidad es el suelo [invisible. de entrada] de la mediación. sobre el cual se liberan [o hacen suya] todas las singularidades. todas las capacidades $y$ todos los azares de cuna y fortuna. $y$ en el cual desembocan las olas de todas las pasiones que solamente son gobernadas por la razón que metiéndose en ellas. aparece. La particularidad. limitada por la universalidad. es la única medida [(sin este límite. desmesurada! cf. Agr. a 185] según la cual cada una de las particularidades promueve su bienestar. 
tección, si queremos hablar como Hobbes, como vínculo totalmente lógico, necesario e inevitable. Más concretamente: sin el estado la sociedad civil se desagregaría hasta hacerse polvo.

Resulta que los dos principios de la sociedad civil tiran en direcciones contrarias: uno desagrega (como la representación), el otro relaciona y une (como el concepto). Se entiende entonces porqué seguidamente Hegel puede hablar «de escisión de la idea ética» o de «disolución del concepto» ( $F D \S 184$ ). Pero lo que creo más importante todavía es que Hegel, contemplando este aspecto de tendencia al desgarramiento en la sociedad civil no busca remedio en el estatalismo totalitario. En él cayó precisamente Platón porque al observar la fuerza disolvente del particularismo no supo encontrarle el lugar y lo proscribió autoritariamente. No, dice Hegel. La particularidad, o sea la sociedad civil, tiene su derecho y hay que respetarlo, y es precisamente a través de la particularidad como la universalidad deviene real: «Promoviendo mi fin promuevo lo universal, el cual a su vez promueve mi fin». Estos aspectos más negativos de la sociedad civil juntamente con el rechazo al totalitarismo estatal se acentúan todavía más en el $\S 185$ con su agregado.

\section{La economía como primer componente de la sociedad civil}

Entrando ahora en un tratamiento más específico, la sociedad civil es ante todo un sistema peculiar de satisfacción de las necesidades, es decir, un sistema económico ( $F D \S 189 \mathrm{ss}$ ). El primer rasgo de nuestra forma de organización económica es que nos encontramos en los antípodas de cualquier economía de subsistencia. Buscándole también una raíz lógica a esta tendencia siempre expansiva o de fuga hacia adelante de nuestra economía, Hegel explica cómo el modo específico de conocimiento que le es propio es la «representación del entendimiento»y no el «concepto 
de razón», la libertad formal y no la libertad real. La representación, en efecto, separa y fija, mientras que el concepto dinamiza y une. De la representación intelectual precisamente resulta el proceso de nunca acabar (de la mala infinitud, dice Hegel) que multiplica indefinidamente las necesidades por un lado y divide el trabajo por el otro $(F D \S \S 190$ y 191). Un proceso que genera inevitablemente consumismo ${ }^{(8)}$.

Todo eso viene a ser la base de la ambigüedad de los resultados de la sociedad civil moderna. Crea una espectacular riqueza pero crea también, de manera igualmente intrínseca, una miseria simétrica ${ }^{(9)}$. La división del trabajo que, cuando es material, puede ser substituída por las máquinas, origina una dinámica hacia un tiempo libre igualmente ambiguo, como se ve en los interrogantes que en nosotros suscita la lectura del $\S 193$. preguntas, sin embargo, que Hegel no se plantea. Tiempo libre sí, pero ¿para qué? Significa necesariamente desocupación para unos y consumismo para otros? Por qué no se crea con él el ámbito de ocio para las satisfacciones

\footnotetext{
(*) El añadido al 191 es una buena descripción de lo que hoy llamariamos sociedad de consumo. In él llegel contempla la indefinitud de los procesos. intrínseca a nuestro sistema económico: "Aquello que los ingleses denominan confortable es cosa del todo inagotable y que va siempre adelante al infinito. pues cada comodidad ensena de nuevo su incomodidad. y lasí| los inventos no llegan jamás a fin. Pero eso. una necesidad no se produce tanto por aquellos que la tienen de manera inmediata. sino más bien por aquellos que buscan una ganancia con su aparición».

$A$ este texto. que se torna intuitivo si se piensa en el automóvil tal como nos vemos forzados a vivirlo hoy en día. cabe añadirle el 193. donde se especifica más la dinámica consumista. in ella interviene como siempre el particularismo. ahora como móvil de los individuos (los primeros consumidores de un producto nuevo se diferencian de los otros exhibiéndolo). pero en seguida aparece la tendencia a la igualación. la que hace posible la venta generalizada del nuevo producto. atendiendo yue los menos afortunados imitan a los primeros usuarios privilegiados.
}

(9) $F D$ ) 185. Este parágrafo inicia desde su raiz el tratamiento del «problema social» que se desarrolla después en los 237-245. Fn ellos se encuentran algunas consideraciones agudas que preludian el estado social de derecho y también sus problemas. 
superiores de la cultura, del arte y de la amistad? La multiplicación de las necesidades fomenta la cultura o intensifica simplemente el progreso tecnológico? $(F D \S 198)$.

Igualmente la sociedad moderna da lugar a una nueva ciencia muy propia de ella: la economía política $(F D \S 189 \mathrm{~N})$. Una ciencia por cierto que, según se lee allí, produce satisfacción intelectual por un lado, pero también asco moral por el otro. Un asco que Hegel, enemigo de moralismos, no ve con simpatía porque no entiende cómo una ciencia que formula necesidades «naturales» de los procesos puede provocar protestas morales.

El grupo de parágrafos 199-208 dedicados a la asignación de bienes producidos (patrimonio) ofrecen un interés particular. Partiendo del carácter social de la producción (riqueza común: $\S$ 199) afirma la necesidad de la desigualdad en el reparto ( $\$ 200)$. Sigue el tratamiento hegeliano de las diferentes clases sociales (o mejor, estamentos, Stände): agricultores, industriales y funcionarios. Los primeros son naturalmente conservadores, pero con tendencia a industrializarse $(\S 203)$, mientras los segundos son naturalmente liberales ( $\$ 204)$. Con los funcionarios hegelianos parece rehacerse el mito platónico del rey filósofo $(\$ 205)$. Este fragmento acaba con la necesidad de escoger profesión (\$207) y se hace enseguida la transición a la administración de justicia mediante la necesidad de proteger la propiedad privada $(\S 208)$. (He aquí una típica transición o Übergang al estilo de Hegel; hay que negar la negación de la propiedad).

\section{$X$. Las administraciones públicas como componentes necesa- rios de la sociedad}

Así, por tanto, el sistema de las necesidades y su satisfacción no es por entero la sociedad civil. La administración de justicia 
y una serie de cuerpos intermedios entre sociedad y estado la completan. Cabe ver por tanto que la economía no lo es todo en la sociedad civil. Administración de justicia en particular, administración pública en general y «corporaciones» son componentes igualmente necesarios. Sin estas instituciones la economía se disolvería, pues por la pugna de las particularidades nos devolvería a la guerra de todos contra todos. Hegel precisa ahora en concreto cómo se lleva a término la acción preservadora de lo universal. Lo hace el estado, emanando de él las administraciones públicas e introduciéndolas como brazo suyo en la sociedad.

En lo que hace a la administración de justicia, los parágrafos 208 y 209 dejan bien claro que la protección de la propiedad es la primera función, no prioritaria, que le corresponde al estado, precisamente como exigencia de la propia sociedad. Hegel se detiene después en el esclarecimiento de qué es ley $(F D \S \S 211-218)$ para pasar seguidamente al estudio de los tribunales y con ellos del dere-. cho procesal ( $\$ \$ 219-228)$. La cuestión en torno al jurado en la $\mathrm{N}$ al parágrafo 228 tiene un tratamiento curioso: el jurado es justificado como derecho de la autoconciencia, a fin de que el esoterismo judicial no la secuestre y someta.

En al $F D$ de la administración pública se dice Polizei, término que quizá se corresponde más bien con el inglés policy que con police. En cualquier caso se traduce mal por «policía». Es suficiente con una lectura superficial del texto para ver que tiene allí un sentido amplio que se relaciona con lo que en España hemos llamado "poder gubernativo», es decir, el poder que ejercen los ministros de Gobernación y los gobernadores civiles. Cierto que comprende en primer lugar el «poder de policía», encargado de la prevención de los delitos, pero tiene también cuidado de los servicios públicos, como la sanidad, la beneficencia, etc. La odiosidad connatural a la función policial hace dificil equilibrar debidamenteel 
poder de la policía con la libertad (§ 234). En lo que hace a los otros servicios públicos, Hegel observa que la sociedad los reclama pero no los cuida en virtud de su propia dinámica egoísta $(\S \S$ 235 y 236). Se puede observar un primer germen de derecho laboral en el $\S 236^{(10)}$, pero sobre todo es interesante el tratamiento de la beneficencia pública, porque en este lugar aparece, muy embrionariamente todavía, la necesidad de cierta redistribución de la renta ( $\$ 237$; cf. también, sin embargo, el $\S 245$ ) como consecuencia de la conflictividad laboral y de la miseria que, juntamente con la riqueza ( $\$ 243)$, genera la sociedad civil. La dependencia de Hegel respecto de fuentes inglesas se hace patente en el $\S 244$ y $\S$ 245. En el final de esta sección encontramos la necesidad de que la fuerza expansiva de la economía moderna encuentre un espacio de comercio exterior y finalmente se extienda por el océano hacia la formación de un imperio colonial ( $\S 246-248)$. El § 249 remacha la doctrina general de la necesidad de seguridad y protección que la sociedad civil demanda y el estado da mediante las administraciones públicas.

Las «corporaciones», como asociaciones que aglutinan intereses particulares y aproximan así la particularidad a la universalidad, hacen la mediación ascendente entre sociedad civil y estado. Vale decir que si la administración de justicia y la administración pública en general son, como decimos, el brazo con el cual el poder político se introduce en la sociedad civil contribuyendo a constituírla, las corporaciones son el brazo civil que introduce intereses en sí mismos particulares, pero generalizados, en la política.

\footnotetext{
(11i) Un estudio del trabajo en la $F D$ debe descansar naturalmente sobre el grupo de parágrafos 196-198. pero creo históricamente interesante perseguir este concepto por otros lugares de la $F D$ donde se encuentra disperso. Sobre todo hay que ver los $\$ \$ 56$ (trabajo como mejor toma de posesión). 66-68 (posibilidad de alienar limitadamente la fuerza de trabajo y sus productos). 80 B) 3) (contrato de trabajo asalariado).
} 
El tratamiento hegeliano de las corporaciones ( $\S \S 250-256)$ continúa el estudio de los estamentos hecho antes ( $\S$ 200-207); textos que resultan hoy especialmente insatisfactorios y hacen inclu-so pensar que ya eran anacrónicos en su tiempo. Hegel se mueve aquí entre reminiscencias o añoranzas gremiales y la necesidad de nuevas corporaciones que, quizá por el uso que hicieron de ellas los fascismos, se nos hace antipático. Sin embargo queda bien subrayada la necesidad de cuerpos intermedios para que el bourgeois no solamente se haga escuchar por el estado, sino para que él mismo se transforme en citoyen.

Todos estos puntos solamente insinuados requieren por sí mismos un estudio más detallado. Aquí solamente han sido evocados a fin de dar una muestra superficial de cómo Hegel encaja los hechos contemporáneos en un contexto teórico que permite interpretarlos como portadores, en su dinamismo, de cierta lógica objetiva.

\section{Concepto hegeliano de estado}

Por lo que hace al tratamiento hegeliano del estado en sí mismo daré también unas indicaciones muy sumarias, aunque según la fama que acompaña el nombre de Hegel es muy posible que su parecer sobre el estado excite más la curiosidad del lector que la doctrina sobre la sociedad civil. También aquí haré primeramente una breve presentación del texto (§ 257) en el cual Hegel define el estado ${ }^{(11)}$. Interpreto que en la primera proposición del texto está contenida la definición entera. Todo lo que sigue es una explicación

\footnotetext{
(11) " \$257. El estado es la realidad efectiva de la idea ética: es el espíritu ético en tanto [es] aquella voluntad manifiesta [o revelada, offenbar]. clara para sí misma y substancial, que se piensa y se sabe. y que lleva a término [o realiza, vollfiuhrt] lo que sabe y en la medida [o hasta el punto, insofern] en que lo sabe. Este espíritu tiene en la costum-
} 
que resalta las dimensiones que lo constituyen. En primer lugar, la definición propiamente dicha: «El estado es la realidad efectiva de la idea ética». El lugar sistemático, y por tanto propio, donde Hegel se explica sobre el significado de las palabras que intervienen en esta definición es su Lógica, la cual viene a ser, en cierto sentido, el diccionario del lenguaje filosófico hegeliano. Aquí doy las referencias en la versión abreviada de estos conceptos que el mismo Hegel hizo en la Enciclopedia de las ciencias filosóficas:

\section{Realidad efectiva, (Wirklichkeit Enz3 $\S 142$ ss $)=« U n i-$} dad devenida inmediata de la esencia y la existencia ${ }^{(12)}$, o del interior y el exterior». Explico: Hegel diferencia las palabras Realität y Wirklichkeit (vg. Enz3 § 91). Realität es cualquier cosa con la cual nos topamos inmediatamente; significa entonces «realidad bruta», sin más especificaciones. Wirklichkeit en cambio, que traducimos por realidad efectiva, es una realidad cualificada, el aspecto externo o existencia de la cual, tal como se nos presenta inmediatamente manifiesta una adecuación lograda (devenida) con la esencia que le es interior y que es el concepto de aquella cosa. Ejemplo platónico: un cuerpo bien formado, un atleta. El cuerpo del atleta,

bre ética [Sitte] su existencia inmediata y en la autoconciencia del singular. [es decir.] en el saber y en la actividad de ella. [tiene] su existencia mediada. de la misma manera que esta autoconciencia. mediante [su] talante [disposición de ánimo. (jesinnung]. tiene su libertad substancial en aquel espíritu como esencia suya. fin y producto de su actividad.

[N] Los penates [o divinidades protectoras de la familia] son los dioses interiores e inferiores. el espiritu del pueblo (Atenea) es lo divino que se está sabiendo y queriendo: la piedad [o veneración hacia los dioses y los padres] es la sensibilidad [que] en sí misma es la eticidad comportándose: la virtud política es el querer del fin pensado [o conocido] que está siendo en sí y para sí».

(12) El lector se puede sorprender de encontrar la palabra "exsistencia» así escrita. con una «s» después de la " $\mathrm{x}$ ». La razón es que Hegel distingue entre Dasein y Existenz. a pesar que las dos palabras en el lenguaje corriente alemán no tienen significado diferente. Dasein es la palabra germánica de uso más común para decir lo que nosotros 
en efecto, es como ha de ser un cuerpo humano; en él resplandece la humanidad (belleza $=$ splendor veri); es como una suerte de prototipo y por eso es efectivo, wirkt, en su acción. Un cojo en cambio no es modélico, no es como habría de ser, su existencia no se corresponde con su esencia, se mueve desgarbado y sin efectividad.

\section{Idea $(E n z 3 \S \S 213 \mathrm{ss})=$ «El verdadero en y para sí, la} unidad absoluta del concepto y de la objetividad». Explico: en la idea culmina lo lógico, es la inteligibilidad pura de la totalidad máxima antes de enajenarse en la naturaleza física. Es lo verdadero por excelencia, enteramente actual (en sí, para sí), porque en ella se halla la adecuación máxima y última (absoluta) entre inteligibilidad y coseidad. No es por tanto una unidad enteramente simple (cosa que excluiría la adecuación), sino que siendo totalidad es unidad y diferencia juntamente.

\section{3. Ética $(E n z 3 \S 233$ y $\$ 513 ; F D \S 142)=$ Idea como} voluntad que se da a sí misma las propias determinaciones, es decir, como voluntad libre o libertad. Cuando estas determinaciones son individuos libres que viven libremente unidos hay eticidad, hay espíritu.

llamamos existencia sin más precisiones. Existenz es palabra menos común: su procedencia latina la hace un poco "extraña» o extranjera para los alemanes y le da automáticamente una tonalidad académina o de tecnicismo filosófico. Hegel se vale de ello y como necesita dos palabras para decir cosas diferentes. aunque próximas. toma las dos y distingue el sentido haciendo una operación semejante a la que hace con Realität y Wirklichkeit. Dasein pertenece a la lógica del ser. como Realität. y significa por tanto la existencia inmediata de los entes que encontramos aquí cualtitativamente diferenciados. Existenz pertenece a la lógica de la esencia y es término correlativo a ella. según la clásica distinción entre esencia y existencia. Más exactamente Existenz se contrapone a la esencia en tanto fundamento. Así se lee en Enz3 $\$ 122 \mathrm{~N}$; eine Existenz geht aus dem Grunde nur hervor: "una exsistencia solamente sale del fundamento". Este "salir» o "proceder de» evoca la etimología latina de ex-sistere según la cual el existente sistit extra causas. Y es eso lo que sugiere al traductor distinguir entre existencia (=Dasein) y exsistencia (o ex-sistencia = Existenz), teniendo en cuenta que nosotros solamente tenemos una palabra disponible para los dos términos alemanes. 
El estado, entonces, como culminación de la eticidad se define genéricamente como realidad efectiva en el sentido explicado, pero no es tampoco cualquier realidad efectiva sino la que es realización lograda de lo que en el orden del conocimiento es la racionalidad máxima (idea) y más precisamente aquí como idea práctica, es decir, como comunidad de voluntades libres.

La explicitación de la definición que el texto hace después concuerda perfectamente con lo que acabamos de decir:

a) El estado es espíritu ético. Espíritu en Hegel es el «concepto más elevado de los tiempos modernos» con evidentes raíces teológicas. Es unidad de lo que se ha diferenciado. Es comunidad libre de individuos libres, no ya en el terreno puramente lógico o eterno, sino en la mundanidad temporal.

b) El estado es voluntad. Pertenece por tanto al orden de la praxis o acción que distinguimos del orden del conocimiento. No es voluntad como accidente o cualidad añadida de nuevo a una sustancia ciega, sino que es la sustancia misma del universo (nueva versión de la sustancia spinoziana) que actúa conscientemente, sabiendo lo que quiere y haciéndolo realidad aquí presente.

c) El estado es costumbre ética. El espíritu-voluntad vive de una manera inmediata (es decir, como ser) en la comunidad que él se ha dado como cuerpo suyo. Este cuerpo es en primer lugar costumbre ética, es decir, estilo de vida que congrega y define una vida colectiva.

d) El estado es, sin embargo, voluntad práctica manifiesta $\mathrm{o}$ revelada; su realidad y su acción son transparentes; no excluye, por tanto, la dimensión cognoscitiva. Eso quiere decir que la acción política no es praxis inconsciente, instintiva o sentimental, sino clara. $\mathrm{Y}$ es consciente de sí en el talante de los individuos que se identifican en ella. Ellos son así sabiduría política; poseen un saber que los supera 
como individuos porque es saber no contemplativo sino activo, y que forma comunidad.

e) El estado es finalmente activo para con sí mismo mediante este talante. La disposición de ánimo o actitud habitual de los individuos identificados con su comunidad hace de mediadora de una $a c$ ción que proviene de la realidad política y acaba en ella. Los individuos encuentran en este talante, de manera casi natural su propia esencia, es decir, su ser más verdadero, su mejor realización. Hacen del fin de la comunidad fin propio, de las tareas comunitarias faena suya.

f) De todo lo cual se desprende que la libertad de los individuos solamente es real en su inserción en la comunidad y mediante ésta. en la libertad absoluta de la substancia.

Creo que una buena ilustración de lo que Hegel dice aquí con su lenguaje enrevesado, sigue siendo el discurso que Tucídides ${ }^{(1.3)}$ pone en boca de Perícles en la ceremonia funeraria en honor de los muertos por la ciudad de Atenas. Los atenienses encuentran en su polis, su mejor ser y su liberación.

La nota al parágrafo enlaza precisamente con las fuentes clásicas. Pero no solamente eso; la nota me parece importante porque enseña además que la comunidad presente, tal como la vivimos aquí y ahora, no es la totalidad de ella misma. Se extiende más allá en el tiempo; pero sobre todo se arraiga en profundidad en lo divino que habita la oscuridad de los muertos que nos precedieron, y habita también, como luz de voluntad racional, en el espíritu colectivo. El sentimiento o disposición reverencial que nos identi- 
fica con estas dimensiones sacras de la vida colectiva es la virtud política. En ella se hace presente la exigencia ética de las finalidades comunes.

No haré más desarrollos del concepto hegeliano de estado. En buena parte ya han sido hechos cuando hemos especificado su relación con la sociedad civil. Una cosa sin embargo subrayarí con énfasis: la definición que acabo de comentar encabeza un primer fragmento del estudio hegeliano del estado donde se trata de cil de la manera más general posible. Vale decir que trata de lo político sin más, antes de tratar específicamente del estado concreto o del estado-nación tal como existe modernamente con su organi/ación interna, con sus relaciones con otros estados particulares y con su inserción dentro del curso histórico que lo provecta hacia un futuru vacío de concreciones. Dicho de otra manera. el estado-nación es solamente una realización de la comunidad política, nu la realización. Y porque es solamente una realización particular $(\$ 3+1)$, resulta «ideal» en el sentido que Hegel da a este adjetivo cuand. evoca lo finito carente de verdad última y desustancializado

\section{Carácter absoluto y carácter no absoluto del estado}

De la pequeña inmersión que acabamos de hacer en el concepto hegeliano de estado se deducen algunas consecuencias en orden a aquella tan denostada divinización hegeliana del estado. Para comenzar, podríamos decir que la divinización hegeliana del estado existe ciertamente, pero no es de ningún modo más grande que la que Hobbes atribuye a su Leviathan ${ }^{(14)}$ : dios mortal sobre la tierra. Pero en lo que hace a Hegel, la divinidad o absolutez, lo que de verdad es principio porque se aguanta solo, porque se mueve

(1+) Thomas Hobbes, Leviathan. cap. XVII. 
sin ser movido, es la libertad como autodeterminación pura $(F D \S \S$ 21-24). Pero no hay que perder de vista que esta libertad no es soledad, sino encontrarse a sí mismo en el otro (bei sich im Anderem). Por eso cuando la libertad se hace real y efectiva se hace comunidad o vínculo bello ${ }^{(15)}$.

Ahora bien, al ser la polis la comunidad más perfecta ${ }^{(16)}$, resulta que la forma moderna de la polis que llamamos estado es todavía más perfecta que la antigua porque ha desarrollado la sociedad civil. Por eso el estado es divino, porque en él reside la autarquía moderna y porque es la última instancia objetiva a la que podemos apelar. Pero es también dios mortal, porque la encarnación de la universalidad que él es recae en la particularidad. La universalidad reside exigitivamente (diría el escolástico) en lo político, pero cuando esta exigencia se hace estado-nación particular no la realiza plenamente. Es una realización máxima (hasta ahora), pero queda aún la universalidad por realizar. Por eso queda también el horizonte utópico de la paz perpetua.

En la primera mitad de este trabajo hemos repetido que la competencia prioritaria del estado es asegurar y promover los valores ligados a la universalidad de los humanos, es decir la libertad. Hemos de decir ahora, sin embargo, que el tratamiento hegeliano del estado según el desarrollo que recibe en la $F D$ resulta a muchos, y a mí mismo, menos satisfactorio y menos sugerente que el análisis de la sociedad civil. Y eso por dos motivos bien diferentes entre sí. El primero, porque Hegel en esta parte de su libro se muestra más temeroso (quizá por la censura), y cuando hace la caracterización de los tres poderes (corona, ejecutivo y legislativo; no el judi-

(15) Platón. Timeo, 32.

(16) Aristóteles. Politica I. 2: 1252 b. 
cial que ya hemos visto que se trata como administración pública inserta en la sociedad civil) resalta su unidad. Exalta la institución monárquica hereditaria (aunque al monarca le reserva poner el punto sobre la «i») y recorta la soberanía popular mal representada en el parlamento bicameral. En conjunto un tratamiento que en la época no era reaccionario, pero que hoy resulta como mínimo anticuado.

El otro motivo para desconfiar del tratamiento hegeliano del estado reside en la opinión o duda de Bobbio, el cual nos parece que introduce una observación de mucho calado. En efecto, Bobbio cree que Hegel en este punto hace lo mismo que critica: decir cómo las cosas han de ser, más que cómo son. Más que analizar instituciones realmente existentes, describe (según esta opinión) lo que el filósofo veía posible en Berlín en aquel momento. Era necesario hacer labor constitucional, sin perder lo mejor de la revolución francesa y de Napoleón, pero sin excitar demasiado, al mismo tiempo, aquella reacción muy viva que contaba con el soporte de Viena. En suma: el estado hegeliano, según esta opinión, no habría existido jamás; ¡sería más bien utópico!

Lo que acabamos de decir es importante porque puede significar, más allá de Hegel, que la política y los estados han estado de hecho subordinados a la sociedad civil. Los intereses particulares y su expansión han estado asegurados y protegidos por el poder político, pero el valor libertad como primero de los derechos humanos y los otros derechos que se le vinculan no habrían sido protegidos y menos aún promocionados. La política de las democracias parlamentarias resultaría así víctima de un secuestro que le impide realizar la función más principal que Hegel le asignaba. La política sería simplemente el resultado de la convergencia de intereses particulares en intereses de más alcance o más generales, pero siempre de la misma especie. Sobre estos intereses se produciría el consenso, y solamente lo consensuado por la sociedad civil pasaría 
entonces a determinación política. La política, en este supuesto, sería cosa semejante a los tratados internacionales de comercio tal como vienen descritos en la primera mitad del $\S 332$ de la $F D$. En este texto, con sarcasmo, reaparece (aunque sea como fantasma) la injuriada doctrina del contrato social. Y este contrato se nos presenta magro y sin substancia en medio de un mar caótico muy hobbesiano ( $F D \S 340$ ), en el cual incluso se esfuma la necesidad de vencer las miserias del azar. Sólo queda la necesidad del horizonte (de momento) utópico y de la historia que no se detiene. Digo bien: que no se acaba porque queda mucha libertad por realizar y queda también, por tanto, mucha historia por correr.

\section{Conclusión}

En cualquier caso, sea por el sometimiento del estado a intereses de la sociedad civil, sea porque el estado-nación es todavía realización deficitaria de las exigencias de la universalidad, los estados actuales padecen mal de soberanía. Los valores verdaderos y necesarios se escapan cada día más de su jurisdicción, hacia un futuro incierto. Hacer un diseño mínimo de este futuro sería tarea de otro día. Sin embargo, sí podemos decir todavía que habría que evitar siempre una pésima tentación bien desenmascarada por Hegel: concebir la política proyectando sobre ella categorías de sociedad civil y de derecho privado. El cuerpo político es y ha de ser órgano de la universalidad y no de la particularidad. Lo que cabe enfatizar es la irreductibilidad de la cosa pública y de la política a la sociedad civil. Sobre esta base, Hegel hace un poco de camino (insuficiente) en dirección a la redistribución de la renta cuando encomienda al poder administrativo la previsión y corrección de la miseria generada por el sistema económico. Pero eso no es todo todavía. La fuerza de su argumentación reside en la irreductibilidad del organismo específicamente político, como cuerpo de la universalidad de la liber- 
tad, a la sociedad civil. Y cabe consecuentementeafirmar que la promoción de los valores de la persona es algo más que redistribución de renta, porque estos valores son humanos, no económicos, aunque en la miseria puedan tener una realización mala y pobre. Valores, sin embargo, que la política no ha de realizar ella misma, sino solamente ofrecer las condiciones de posibilidad para que la persona misma los realice.

Es en el tratamiento de la política como algo superior a la sociedad civil donde Hegel se gana, parece, la acusación de estatalista, de totalitario. Si estudiamos la cuestión con cuidado, sin embargo, vemos que estas censuras proceden del esfuerzo de la sociedad civil para subordinar a ella el poder político exigiéndole que se limite a la sola protección y seguridad de los intereses particulares. La contraargumentación hegeliana, filosófica si la hay, ante estos intentos sigue siendo fuerte, no debole. 